\title{
THE 'STIFF MAN SYNDROME' IN A BOY
}

\author{
BY \\ DAVID BOWLER \\ From the Paediatric Unit, Penang General Hospital
}

(RECEIVED FOR PUBLICATION JULY 10, 1959)

Tetanus is common in Malaya, and the case to be described, although first diagnosed as recurrent tetanus, is put forward as a case of the "stiff man syndrome' or progressive fluctuating muscular rigidity and spasm.

\section{Case Report}

In October, 1958, a Chinese boy, aged 7 years, was transferred to the Children's Unit with a diagnosis of recurrent tetanus. According to the mother, he had been ill intermittently since 1957 when he was first admitted to hospital complaining of stiffness of the body and inability to open his mouth. He apparently recovered from this illness, but was readmitted on two further occasions with similar complaints. For over one year he had been unable to open his mouth properly. Since August, 1958, this difficulty had increased so that taking solid food was impossible and he had been fed on fluids only. From time to time during the past year his face had 'twisted up' (mother's description). His mother had brought him to hospital again because for the last month he had been 'stiff all over' and had been having 'fits'. She was quite certain that he had never had any injury, and that before 1957 he had been quite well. He had never been immunized. There were five other children in the family, all of them well.

He had been in different hospitals three times. On his first admission in February, 1957, he had complained of trismus and stiffness of the back and abdomen. He was treated as a case of tetanus, although there was no history of injury, and he had no typical tetanic spasms whilst in hospital. He was admitted on two further occasions in April, 1957, and January, 1958. Each time his complaint was difficulty in opening his mouth, but rigidity of the abdominal muscles (they were described as 'board-like') was noted on examination. There was no involvement of the arms and legs, and the child was able to walk. In January, 1958, recurrent left facial spasms were noted for the first time.

On each occasion the stiffness disappeared in about three weeks and he was discharged, although the inability to open his mouth remained. No investigations were carried out, and no firm diagnosis was made.

In summary, therefore, since February, 1957, the child had suffered from a recurrent illness involving stiffness of the abdominal muscles, together with difficulty in opening his mouth. The latter complaint had become permanent and was associated with left facial spasms.

When seen by me in October, 1958, the child was conscious, alert and lying quietly in bed. He lay like a 'wooden soldier' with the head, trunk, arms and legs quite straight. The feet were plantar flexed and the hands were in the mains d'accoucheur position. There was a suggestion of risus sardonicus about the mouth, and the muscles of the neck, chest, abdomen and back were tense, clearly outlined, and appeared to be in a state of permanent contraction. There was no opisthotonus although there was marked neck stiffness due to the rigid neck and trunk muscles. The abnormal appearance and

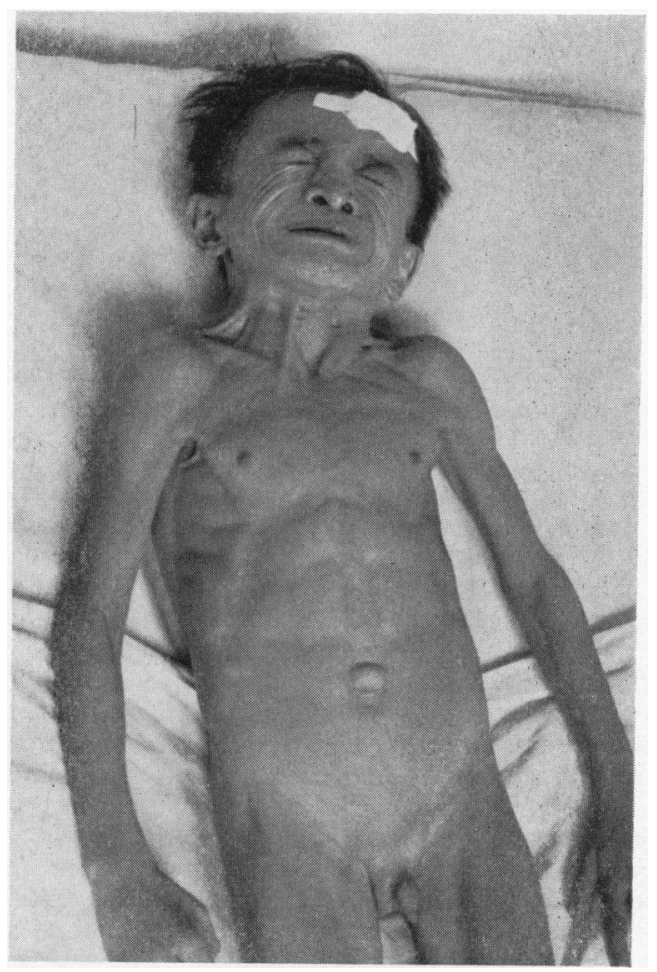

FIG. 1.-Appearance of child during a spasm. 
feel of the muscles were absent in the legs and in the forearms.

The child was intelligent and cooperative throughout what appeared to be a most painful physical examination. When at rest he was quiet but when examination was attempted there were violent intermittent spasms of the face and neck muscles. Each spasm lasted about 30 seconds, was accompanied by profuse sweating and appeared to be extremely painful. The similarity to tetanus was marked, although the child was emphatic that the spasms were painless. They were precipitated by efforts to talk, to open the mouth, tapping the face, movements of the arms and legs, and by nursing procedures (Fig. 1).

The other muscles of the body, although remaining rigid, were not involved in the spasms. The child could open his mouth $0.5 \mathrm{~cm}$. only (Fig. 2). It was interesting

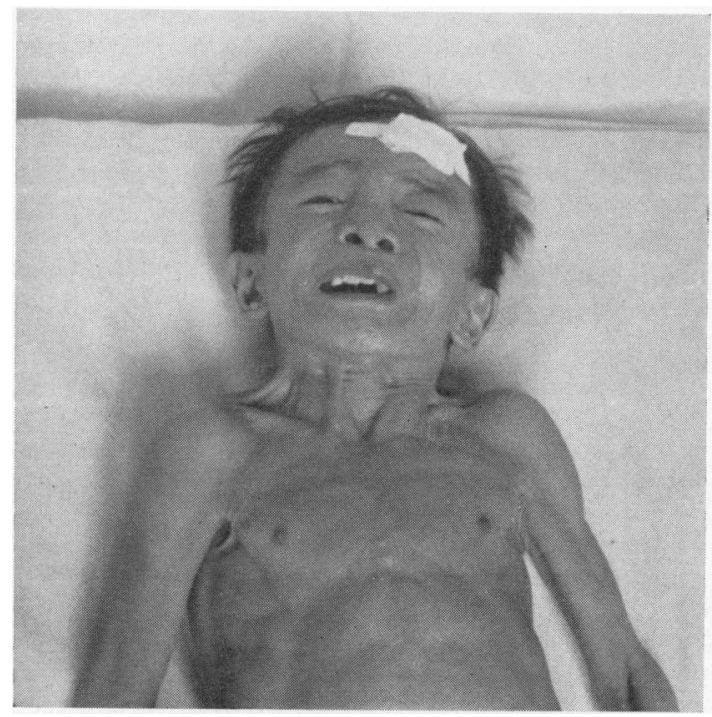

FIG. 2.-Demonstrating inability of child to open mouth.

to note that the feel of the edge of the masseter muscles, which is so characteristic in tetanus, was absent in this child. Neither was any jaw jerk obtained. The child was unable to sit, turn in bed, or to stand. When he was supported on his feet there was an immediate increase in the rigidity of all muscles, including the limbs, together with the most violent spasms of the face and neck. The muscles of the trunk were hard and unyielding, and the abdomen was board-like. The feet became strongly plantar flexed. The child remained stiff and straight when lifted from the bed (Fig. 3) but could be 'bent' into a sitting position.

Passive movements of the limbs showed some 'lead pipe' rigidity greater in the legs than in the arms. Active movements were carried out slowly, and power and coordination were poor, being limited by the stiffness. There was no weakness nor wasting of any particular muscle group, and there were no involuntary movements (apart from the spasms), tremors, or muscle fibrillation. The limb reflexes were normal and there were no sensory abnormalities. During sleep the child was relaxed and the muscles were quite soft. Examination of the heart and lungs revealed nothing remarkable.

The child remained in hospital for 30 days during which time the stiffness and rigidity of the muscles slowly regressed, regression being uniform throughout the affected muscles. The spasms became less violent and frequent and there was some improvement in his ability to open his mouth. Two weeks after admission the child was able to walk, but with a wooden stiff-legged gait. If he lost his balance he fell forward completely stiffly. At no time during his stay did he complain of any muscular pain. Apart from a high protein diet enriched with vitamins he received no specific treatment.

At the time of his discharge he was fairly active. There was no stiffness nor tenseness of the muscles. The spasms had ceased and he could open his mouth $1.5 \mathrm{~cm}$. He disliked trying to run because he said his legs felt heavy. Since discharge he has been seen regularly and has remained almost free from symptoms. He is still unable to open his mouth fully and he dislikes running. His mother says that occasionally his face 'twists up'.

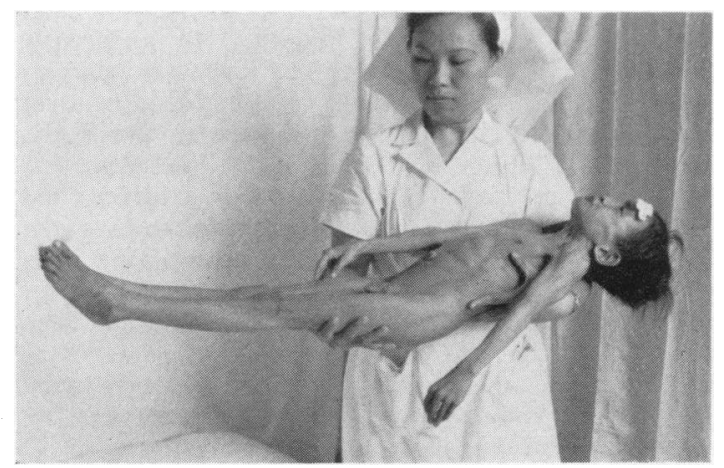

FIG. 3.-Demonstrating overall rigidity of child when lifted.

Whilst in hospital he was investigated in detail. Blood biochemistry was normal $\left(\mathrm{Na} ; \mathrm{K} ; \mathrm{Ca} ; \mathrm{CO}_{2}\right.$ combining power; inorganic phosphate; plasma proteins; blood urea). A four-hour glucose tolerance test with simultaneous phosphate estimations was normal. Liver function tests were normal, cerebrospinal fluid examination was normal, as was the electrocardiograph. Radiographs of the skull and temporo-mandibular joints showed no lesion to account for his inability to open his mouth. The urine was tested repeatedly for reducing substances but they were absent on all occasions. Muscle biopsy was not performed.

\section{Discussion}

For want of a more accurate term the stiff man syndrome has been used to describe this case. 
Moersch and Woltman (1956), who first described the condition, labelled it more accurately progressive fluctuating muscular rigidity and spasm. They record having seen 14 cases (all adults) in 32 years. In the case they described in detail there was episodic tightening of the muscles of the neck, which gradually increased in frequency, duration and extent. Four years after the onset of the disease the neck muscles were permanently rigid, as were the muscles of the trunk, abdomen and back. The rigidity was punctuated by moderately painful spasms, which were precipitated by a sudden jar or voluntary movement. Twelve years after the onset of the symptoms he still had the muscle rigidity and the spasms. Of the other 13 cases summarized, stiffness, rigidity or tightness was the chief initial complaint. All cases had experienced spasms, but these were not always painful or marked. Ten of the cases had a gradual onset and the muscles of the neck or trunk and shoulder were first affected. In all cases the stiffness spread to other muscles. Involvement of the hands and feet was minor, and the face was not involved in any case. In no case was there any mental deterioration. The cases were followed up from three to 14 years, and in all except one there was a gradual increase in the disability. All cases were notable for the complete lack of other physical signs, the failure of investigations to reveal any abnormality and the failure of all treatment to influence the course of the disease. Asher (1958) and Price and Allott (1958) describe adult cases of this syndrome. In both cases, however, the descriptions differed from Moersch in that the feet and legs were heavily involved, causing a pronounced talipes equinovarus. In Asher's case there were additional mental changes. Similarly, the present case differed from the description of Moersch in that there was marked involvement of the face, although in other respects the similarity was close.

If this syndrome is to be admitted as an entity, therefore, it seems that any group of muscles may be involved initially and that the course of the disease is subject to wide variations. The only common factor is the fluctuating rigidity, coupled with an almost complete lack of other abnormal findings, and the failure of all forms of treatment.

Clinically the syndrome resembles recurrent tetanus in many ways. True second attacks of tetanus in the same patient are very rare. I have found only two clear references in the literature (Möbus, 1950; Gunaratna, 1958). Westwater (1917) mentions a case, but as the attack followed a gunshot wound, and as it is not clear whether the case had any surgical treatment, this case may be a recrudes- cence due to the persistence of a foreign body. It is surprising that so few cases of true second attacks of tetanus are on record, since a clinical attack of tetanus does not give any immunity to subsequent attacks (Spaeth, 1949). Professor Adams of Durban states that in a series of 360 cases of tetanus he has not seen any true second attack. Chronic recurrent tetanus due to the persistence of a foreign body or focus of infection in the tissues is relatively well known (Mouchet, 1916; Adams,1958). The clinical picture of tetanus can vary very widely, with few or many muscle groups involved, and with any degree of hypertonus. The tetanic spasms may be absent or present in any degree of severity.

Nevertheless, the picture of the stiff man syndrome, when viewed as a disease process in time, is quite unlike that of tetanus, and on clinical grounds alone it is reasonable to assume that there is no relation between the two conditions.

It has been suggested (Leading article, 1956) that the stiff man syndrome may be due to degenerative changes in the basal ganglia and that the syndrome is a variant of dystonia musculorum deformans. Superficially there are similarities between dystonia and the stiff man syndrome. Wechsler and Brock (1922) described a variant of dystonia in which the involuntary movements were largely absent and in which muscle rigidity was the predominant disability. In both dystonia and the stiff man syndrome muscle stiffness and rigidity, which slowly spreads, is the presenting disability. The end result of both diseases is associated with deformities. In dystonia, however, involuntary movements are a marked feature of the disease and there are often mental changes (Ford, 1952). However, apart from muscle spasm and stiffness, the two syndromes appear to have little in common. Although the present case has not been followed long enough, all the other reported cases showed no clinical evidence of degenerative brain changes.

I have thought it of interest to report this case since, like the cases reported by others, it does not appear to fit any recognizable condition, and so far the syndrome has been reported only in adults.

\section{Summary}

A case of the stiff man syndrome or progressive fluctuating muscular rigidity is described. The condition is briefly reviewed.

\section{REFERENCES}

Adams, E. B (1958) Personal comcenication.

Asher, R. (1958). A woman with the stiff-man syndrome. Brit

Ford, F. R., (1952). Diseases of the Nervous System in Infancy, Childhood and Adolescence. Blackwell, Oxford.

Gunaratna, N. P. S. (1958). A case of recurrent tetanus. J. Lady Ridgeway Hosp. Child., 7, 3. 
Leading Article (1956). Stiff-man syndromes. Brit. med. J., 2, 1478. Moersch, F. P. and Woltman, H. W. (1956). Progressive fluctuating muscular rigidity and spasm ('stiff-man' syndrome): report of a case and some observations in 13 other cases. Proc. Mayo Clin., $31,421$.

Möbus, L. (1950). Uber atypischen und rezidivierenden Tetanus. $Z$. Kinderheilk., 68, 427.

Mouchet, A. (1916). Chronic recurrent tetanus. Med: Press, n.s. 101, 28 .

Price, T. M. L. and Allott, E. N. (1958). The stiff-man syndrome; preliminary report of a case. Brit. med. J., 1, 682

Spaeth, R. (1949). Tetanus immunity. J. Amer. med. Ass., 141, 238.

Wechsler, I. S. and Brock, S. (1922). Dystonia musculorum deformans, with especial reference to a myostatic form and the occurrence of decerebrate rigidity phenomena. A study of cases. Arch. Neurol. Psychiat. (Chicago), 8, 538.

Westwater, A. M. (1917). A case of recurrent tetanus. Brit. med. 黑, 1, 395 .

\section{Addendum.}

Since submitting this paper, a case of recurrent tetanus has occurred at this Hospital, under the care of Mr. S. M. Alhady, details of which will Be reported later. 